\title{
A teia da informação e os desafios dos gestores do varejo de moda
}

\author{
The information web and its challenges to fashion retail managers
}

\begin{abstract}
Valeria Ayres Magalhães Mestre em Ciência da Informação pela Universidade Federal de Minas Gerais - UFMG, Brasil. Docente do Programa de Pós-Graduação do Instituto de Educação Continuada da Pontifícia Universidade Católica de Minas Gerais, Brasil. E-mail: vaayres@yahoo.com.br

Helena Maria Tarchi Crivellari Doutora em Educação pela Universidade Estadual de Campinas - UNICAMP, Brasil. Professora da Escola de Ciência da Informação da Universidade Federal de Minas Gerais - UFMG, Brasil. E-mail: helenacrivellari@gmail.com ORCID: https://orcid.org/0000-0003-1615-9780
\end{abstract}

\section{Resumo}

$\mathrm{O}$ artigo aborda o processo de busca de informações de gestores de lojas de varejo de moda. Baseado em resultados de pesquisa de mestrado, que estudou empresas de micro e pequeno porte de Belo Horizonte, o artigo tem como objetivo focar as dificuldades enfrentadas pelos gestores. Do ponto de vista teórico, centrou-se em elementos da sociologia da moda e na proposta das três arenas de Choo, elaborada a partir de modelos de busca de informação, a saber: Sense-Making, Information Seeking Process - ISP e Modelo Situacional. A metodologia do estudo empírico englobou um processo quanti/qualitativo, com aplicação de questionários, seguido de entrevistas semiestruturadas com os gestores. As conclusões apontam a existência de diversas dificuldades decorrentes da rotina desses lojistas de moda; além disso, observou-se que alguns entraves relevantes são fruto de uma especificidade do campo da moda o excesso de informações, produzidas por diversas fontes e agentes, formando uma teia complexa de dados e informações.

Palavras-chave: Busca de informações. Gestão do conhecimento. ALI SEBRAE. Varejo de moda. Micro e Pequena Empresa (MPE).

\begin{abstract}
This article analyses the process of information seeking by managers of fashion retail stores. Based on results of a master's research, which studied micro and small companies in Belo Horizonte, the article aims to focus on the difficulties faced by owners and managers. The study was based on Choo's proposal of the Three Arenas, elaborated from models of information seeking, namely: Sense-Making, Information Seeking Process - ISP and Situational Model. The methodology of the empirical study included a quantitative / qualitative process, with questionnaires, followed by semi-structured interviews whith the managers. The conclusions indicate to the existence of several difficulties arising from the routine of these fashion retailers; in addition, it has been observerd that some relevant obstacles are the outcome of a specificity of the fashion field: the excess of information, produced by diverse sources and agents, forming a complex web of data and information.
\end{abstract}

Keywords: Knowledge management. Information seeking. ALI SEBRAE. Fashion retail. Micro and Small Business. 


\section{Introdução}

O setor da moda gera abundante teia de informações em toda sua cadeia produtiva. Dispõe, no contexto informacional, de várias entidades e fontes proponentes de conhecimento e informação, cada vez mais presentes em meio digital, bases de dados, nos sistemas internos das empresas e em outros canais.

Esse artigo tem como universo de estudo lojas de varejo de moda de micro e pequeno porte, em Belo Horizonte $(\mathrm{BH})$ e região metropolitana, que participaram de um programa avançado de Gestão para a Inovação: o ALI SEBRAE CNPq ${ }^{1}$. O estudo, no qual se baseia o presente texto, foi realizado para pesquisa de mestrado em Ciência da Informação (CI), na Universidade Federal de Minas Gerais (UFMG), utilizando elementos de pesquisa quantitativa e, posteriormente, foi feito estudo qualitativo de caso em seis empresas selecionadas. A pesquisa foi realizada com uma amostra não probabilística por julgamento e o intuito do estudo era verificar o processo de busca informacional de empresários e gestores das empresas pesquisadas, as dificuldades e facilidades encontradas por eles, além de identificar questões relacionadas ao perfil de empresas que pudessem impactar na trajetória de busca de informações.

Em linhas gerais, quanto ao perfil das micro e pequenas empresas - MPE's - estas correspondem a 27\% do Produto Interno Bruto (PIB) brasileiro, chegando a 53,4\% no setor do comércio, segundo dados do Serviço Brasileiro de Apoio às Micro e Pequenas Empresas (SEBRAE). Estudos da mesma fonte indicam que a falta de informações, seu uso inadequado e o baixo conhecimento sobre o mercado estão entre os principais fatores de insucesso das empresas (SEBRAE/SP, 2014). Estudiosos sobre a questão, como Drucker (2011) e Porter (1989) creditam parte do insucesso ou da mortalidade desse tipo de empresas a fatores como a falta de informação e conhecimento, inexperiência, falta de crédito e falta de formação gerencial.

A pesquisa realizada avaliou as fontes de informação de moda mais buscadas pelos gestores; os sistemas de gestão de loja existentes nas empresas e o contexto da busca de informações, envolvendo tais gestores. Procurou analisar os modos como se dão as atividades

\footnotetext{
${ }^{1}$ Agradecimentos, por autorizar a pesquisa, ao ALI SEBRAE CNPq - Programa Agentes Locais de Informação, focado nos processos de gestão e inovação das empresas e que enfatizam a busca e uso da informação como diferencial competitivo. Nesse programa, existe um Módulo de Busca de Informação, que é apresentado aos participantes como um dos elementos fundamentais para a inovação: as empresas passam por um processo de entendimento sobre a importância em buscar e recuperar a informação a partir de fontes de seu interesse.
} 
dos sujeitos quando percebem a necessidade de informações e vão à busca dessas informações, para então fazerem uso das mesmas. $\mathrm{O}$ foco adotado no estudo foi o da chamada Information Seeking, processo que leva mais em conta os aspectos humanos e comportamentais - para além da questão tecnológica e da recuperação técnica da informação. Tal enfoque é proposto por autores como Kuhlthau (1991), Wilson (1999), Dervin, Foreman-Wernet e Lauterbach (2003), Choo (2003) e está centrado nos problemas do usuário e na produção de sentido, salientando a eficiência da recuperação de informação e levando em conta a integração dos resultados na vida do usuário e na avaliação que ele faz da utilidade da informação para a solução de seus problemas.

O artigo mostra em seguida, na seção "A moda e a informação de moda", o contexto de moda e do varejo de moda que envolve o universo pesquisado, para destacar características do setor e suas empresas que podem inferir nos comportamentos informacionais de seus gestores.

$\mathrm{Na}$ seção "As micro e pequenas empresas de varejo da moda em BH: inovação e informação", é apresentado um escopo sobre perfil das Micro e pequenas empresas e o processo de inovação. Na seção "Os processos de busca e uso da informação no âmbito da Gestão do Conhecimento" é feita uma referência ao conceito da Gestão do Conhecimento (GC) e especialmente ao processo de Busca de Informações. Destaca-se nessa seção a proposta das Três Arenas de Choo (Criação de Significado, Construção de Conhecimento e Tomada de Decisões), que foi usada como base para o estudo, especialmente focando na percepção de como os gestores de varejo de moda buscam a informação, apontando ou não para uma tendência maior a uma das arenas. A proposta de Choo (2003) se baseia ainda em três modelos informacionais que também foram considerados nesse estudo, para analisarmos os comportamentos de busca de informação desses gestores. Os modelos inseridos na proposta de Choo são: o modelo de Sense-Making, de Brenda Dervin (1996), o modelo ISP - Information Seeking Process de Carol Kuhlthau (1991) e o Modelo de Taylor (1991), que prioriza o situacional.

Na seção seguinte o artigo apresenta a seção metodologia utilizada para em seguida, na seção "Resultados Obtidos" discorrer sobre as percepções e resultados verificados. A última seção mostra as considerações finais da pesquisa. 


\section{A moda e a informação de moda}

A moda é compreendida, neste artigo, sob o ponto de vista histórico, social e econômico. Para se estudar o processo de busca de informações no varejo de moda, é importante considerar as condições geradas pelo setor e a influência da moda nos hábitos sociais. Este olhar sobre a moda ajuda a caracterizar sua influência sobre as sociedades, sobre as dinâmicas sociais e comerciais, e ainda possibilita discorrer sobre aspectos específicos do setor em relação às formas de atuação dos seus agentes, em especial no que se refere à busca de informações.

O termo moda não designa apenas vestimentas e acessórios, mas também hábitos, atitudes e comportamentos. Afinal, como lembra Albino (2000), a moda não tem conteúdo próprio ou forma, e não está ligada apenas a roupas e objetos, mas sim apresenta-se como um dispositivo social que atua em diversos campos, desde a decoração, vestuário, artes, entre outras áreas.

Nas sociedades primitivas, os homens iniciaram a manipulação de matérias primas naturais para a produção dos primeiros trajes. Childe (1981) lembra que surgiram as primeiras experiências do homem com os animais de forma a poder aproveitar não só sua carne, mas também peles e lã, na criação de vestimentas para aquecimento e defesa do frio. As vestimentas e adereços estavam, então, ligados também a questões culturais, como a adoração a deuses e ritos sociais.

As mudanças e adaptações das vestimentas aparecem, historicamente, atreladas a um processo de identidade cultural e, ainda, à evolução das relações comerciais desde os primórdios das relações capitalistas, com o deslocamento constante entre os grandes centros e organizações de sociedades e cidades. Aumenta, assim, a intensidade do comércio, com a organização dos processos artesanais, fabris, a oferta de produtos para os "mercados" e a maior circulação de mercadorias.

Feghali (2013) indica a importância de se perceber a moda como um processo e não apenas a vestimenta em si. Até o século XV, pode-se discutir as variedades, usos e funções das vestimentas. O que marcou a mudança e permite se falar efetivamente em moda foi a instalação do seu aspecto social. Conte (2015) reforça como o universo da moda amplia as relações sociais e apresenta uma riqueza de informações considerando seus diversos agentes. Moda é mais que roupagem e vestimentas. 
Lipovetsky (2009) afirma que a moda, no sentido que o termo detém hoje - o de sistema formador de comportamentos - decorre das inovações e produções embasadas, não no acaso, mas na consciência da criação e procura de produtos, para uma diferenciação de classes, distinção social, a busca do reconhecimento (ver também Bourdieu, 2001).

Bourdieu (2001) destaca como os costureiros marcaram época a partir da introdução dos estilos na moda. As grandes marcas propõem moda e estilos de acordo com a lógica dos costureiros. Paralelamente, os recém-chegados ao mundo da moda propõem reformas, novos olhares e estilos, ativando uma dinâmica entre os agentes criadores da moda, que dá um tom de continuidade às referências reconhecidas, mas, por outro lado, traz um tom de transgressão e rejeição. A moda tem caráter transitório, a partir de suas relações sociais, que impõe uma renovação constante, uma imitação do presente e uma tendência de movimento e proposição de novidades.

A primeira revista a inserir assuntos de moda em seu conteúdo foi a Mercure Galant, ainda em 1672, segundo Blackman (2012), e desde então esse material não parou de crescer. Atualmente, a informação de moda atinge dimensões amplas, mídias diversas, acessos abertos, bem como agentes publicadores ou criadores de informação em várias esferas - do especialista ao generalista, do cético e crítico ao apaixonado. Estudos científicos em várias áreas, dados estatísticos, informações sobre consumo são apenas parte da profusão de fontes de informação em torno do tema. Para Lipovetsky (2009), a moda produz o melhor e o pior em termos de informação, gerando dados 24 horas por dia e o "grau zero de pensamento" em algumas situações, em função do universo da sedução ou do show biz.

Percebe-se, pois, uma amplitude de agentes inseridos nesse meio - produtores de moda, propagadores, questionadores, usuários, especialistas, interessados em moda, entre outros. E uma variedade e velocidade de conteúdos e abordagens. O produto de moda se estabelece como um bem simbólico, de caráter econômico, mas também sociocultural, em constante transformação. A complexidade da informação complementa esse cenário (ALBINO, 2000).

Após a I Guerra, simultaneamente se desenvolveram a alta costura e a produção industrial. Nesse contexto, segundo Blackman (2012), a comunicação toma uma nova significação, com disseminação de conteúdos de forma mais rápida e ampla. As máquinas e processos produtivos evoluíram rapidamente, assim como as relações sociais. A indústria de moda, embora inspirada na alta costura, passa a produzir em larga escala: produtos de qualidade 
para um perfil de mercado com renda mais elevada e produtos de massa, para mercados mais populares. É o prêt-à-porter ou, traduzindo, pronto para usar.

Os anos 60 foram fundamentais para a ampliação das boutiques e pequenas lojas, em oposição às grandes lojas de departamentos ou às exclusivas maisons de luxo.

O Fast-Fashion é o modelo de negócios para a moda que está, atualmente, em evidência e desde os anos 90, com a evolução das grandes cadeias comerciais e de distribuição de produtos, nacionais e internacionais, que adotam conceito de difusão e distribuição de moda, de forma abrangente (CIETTA, 2010). Além da característica de rapidez entre a produção e entrada do produto nas lojas - como o próprio estilo se denomina - tal conceito implica também uma política comercial orientada para segmentos específicos de consumidores, que permite a agilidade, por oferecer produtos em tamanhos específicos, estilos e coleções baseadas nas tendências mais recentes de moda e criação de marcas prontas.

O final do século XX e o século XXI veem a moda sob um novo olhar social, saindo do conceito de moda tradicional para um contexto contemporâneo do consumo de massa, de criação de modas plurais e tendências múltiplas (DULCI, 2009) e de aceleração do conteúdo de moda. As blogueiras e os influenciadores digitais se tornam cada vez mais presentes, gerando conteúdos e debates no setor.

No varejo, novas e mais ágeis formas de comercialização dão o tom de vendas dos produtos, no meio presencial ou virtual. Galerias, grandes centros de consumo estão pulverizados em regiões de circulação de público, nos centros ou locais de potencial econômico. Formatos alternativos de loja são constantemente lançados, e a criação de ambientes mistos de consumo, entretenimento e cultura passam a integrar as dinâmicas comerciais.

Em se tratando das dinâmicas comerciais e da aceleração do conteúdo de moda, o campo apresenta uma peculiaridade no que diz respeito a suas fontes - que já citamos como sendo amplas, formadas por especialistas e não especialistas e difundida em rede (virtual ou presencialmente), com os influenciadores de informações acelerando a dinâmica dos conteúdos técnicos e não técnicos do mundo fashion. A partilha de opiniões e experiências dos consumidores, produtores e diversos agentes da cadeia é uma característica muito marcante no campo da moda, em que as comunicações são amplamente divulgadas, seja em ambientes digitais, eventos, ações promocionais, seja no ambiente de lojas. 
A questão citada anteriormente, com base em Lipovetsky (2009), que aponta a informação ou desinformação, pode ser percebida, a partir de um olhar sobre as influências dos produtores de informação. A informação disponível a baixo custo e com fácil acesso é amplamente explorada. Se, por um lado, os próprios consumidores passam também a ser “especialistas" de conteúdo, por outro, existe uma intervenção das empresas e marcas, que se organizam de forma a gerar e promover ações de marketing e divulgação no meio digital.

\section{As micro e pequenas empresas de varejo da moda em BH: inovação e informação}

No Brasil, a Micro Empresa se caracteriza por ter faturamento anual de até R\$ 360.000,00 e a Pequena Empresa, de até R\$ 4.800.000,00. Segundo SEBRAE (2016), as atividades de comércio e serviço perfazem 18,7\% dessas empresas e, em pesquisa realizada pela entidade, grupos de fatores contribuem para a sobrevivência ou mortalidade dessas empresas, destacando-se entre elas: “(1) o tipo de ocupação dos empresário antes da abertura (se desempregado ou não); (2) a experiência/conhecimento do empresário anterior no ramo; (3) a motivação para a abertura do negócio; (4) o planejamento adequado do negócio antes da abertura; (5) a qualidade da gestão do negócio; e (6) a capacitação dos donos em gestão empresarial” (SEBRAE, 2016, grifo nosso).

Na região metropolitana de Belo Horizonte, há 175.775 empresas de micro ou pequeno porte, sendo 60.851 (34,2\%) no setor de comércio, que, por sua vez, emprega $40,61 \%$ dos funcionários de MPE’s (SEBRAE, 2017).

Para aperfeiçoar a gestão dessas empresas, o SEBRAE criou o programa Agentes Locais de Inovação - ALI, que visa estruturar um processo de planejamento e acompanhamento das empresas, com foco em aumento de competitividade a partir da disseminação da cultura da inovação. A metodologia, proposta pelo próprio SEBRAE e pelo Conselho Nacional de Desenvolvimento Científico e Tecnológico (CNPq), em nível nacional, contempla a realização de um diagnóstico inicial nas empresas, e, em seguida, a proposta de planos de ação e processos, acompanhados por bolsistas do CNPq.

O Programa fez o acompanhamento das empresas durante dois anos e meio (de julho de 2015 a dezembro de 2017), com visitas mensais dos agentes para identificar evolução das empresas no processo de inovação. Nesse período, as empresas tiveram um processo de desenvolvimento dos pilares de inovação, sendo um deles a informação. No Programa ALI SEBRAE, na regional de Belo Horizonte haviam aproximadamente 800 empresas sendo InCID: R. Ci. Inf. e Doc., Ribeirão Preto, v. 11, n. 1, p. 114-134, mar./ago. 2020. 
acompanhadas, sendo 220 do setor de moda. Foram essas empresas do setor de moda que compuseram o universo estudado na pesquisa que gerou esse artigo. Em termos de localização no universo de empresas que fazem parte da pesquisa, a maioria das empresas é de Belo Horizonte (191), sendo as outras de Betim (13), Contagem (5), Nova Lima e Santa Luzia (1 de cada cidade). Os tipos de produtos comercializados pelas empresas as caracterizam como lojas de roupas femininas, masculinas, infantis, locação de vestuário, moda noiva, moda festa, calçados e acessórios de moda.

O processo de inovação, tal como entendido pelos organizadores do Programa, com base no Manual de Oslo (1997), é favorecido por diversas fontes de informação internas (de dentro da empresa) e externas (fontes de mercado, educacionais, institucionais). De acordo com o Programa, a informação é ressaltada como fator que facilita a inovação, e são avaliados indicadores de evolução das empresas no processo de inovação respaldados pela análise da trajetória da busca e uso das informações por parte dos empresários participantes do ALI.

A opção pelo universo de gestores e empresários do ALI se deu por fazerem parte de empresas com um processo de gestão mais avançado, que contempla a gestão da informação como um diferencial competitivo.

\section{Os processos de busca e uso da informação no âmbito da Gestão do Conhecimento}

A Gestão do Conhecimento (GC) engloba as noções de dado, informação e conhecimento - definição, no âmbito empresarial, para a aplicação de processos e ferramentas de criar, transformar e usar o conhecimento nas organizações em busca de competitividade. Pela definição de Davenport e Prusak (1998), a GC pode ser vista como uma coleção de processos que governa a criação, disseminação e uso do conhecimento para alcançar as metas e objetivos das empresas. A área tem foco de estudos e abordagens que contemplam o universo informacional, seus processos e trajetórias como instrumentos de gestão, com um olhar sobre as questões sociais, culturais e contextuais relacionadas aos processos informacionais.

Entre os modelos de GC, destacam-se autores como Nonaka e Takeuchi (1997), Wilson (1999), Choo (2003), Brenda Dervin (1996). Alguns dão maior destaque para o comportamento de uso da informação; outros, para processo de busca de informações.

Para o presente artigo, merecem especial atenção os trabalhos de Choo (2003), autor que propõe um modelo de percepção da necessidade de informação, de busca e 
compartilhamento, que pode ser aplicado em empresas. Sua proposta tem uma visão holística do processo e a evolução do conhecimento no contexto da organização a partir da dinâmica informacional. Choo (2003) apresenta sua proposta trazendo outros autores e conceitos para relevar o estudo de necessidades e usos da informação. $\mathrm{O}$ autor supracitado propõe três arenas: criação de sentido (Sense-Making), construção do conhecimento (com a aprendizagem organizacional) e tomada de decisão.

Na arena de Criação de Significado, ou criação de sentido (Sense-Making), o desafio das empresas e seus gestores é entender e gerar um consenso sobre o que é a organização e o que ela faz. $\mathrm{Na}$ arena de Construção do Conhecimento (com a aprendizagem organizacional), a organização cria, organiza e processa a informação de forma a gerar novos conhecimentos a partir do aprendizado. Na terceira arena, de uso estratégico da informação, de Tomada de Decisão, as organizações buscam e avaliam as informações para tomar decisões.

O modelo proposto por Choo (2003) divide o processo de uso da informação em três estágios conceituais, não ordenáveis, que são de entendimento da necessidade de informação por parte dos indivíduos. Para o autor, "a necessidade, busca e uso ocorrem em ciclos recorrentes, que interagem sem ordem pré-determinada" (CHOO, 2003, p. 111), e o processo é dinâmico.

Quando o sujeito percebe uma necessidade de informação, não necessariamente parte para a busca. A partir do momento em que a necessidade se torna mais evidente e se "organiza" um foco é que a busca será possivelmente iniciada. Ao ter contato com fontes, por exemplo, o sujeito pode perceber novas necessidades de informação e formular novas questões. No estágio da busca, Choo (2003) observa uma estrutura mais perceptível, em termos de etapas. O sujeito engaja-se decididamente ou de forma dedicada ao processo de busca da informação para satisfazer sua necessidade e que é capaz de mudar seu estado de conhecimento.

O processo de busca apresenta comportamentos que passam por iniciar, encadear, vasculhar, diferenciar, monitorar, extrair, verificar e finalizar. "A intensidade com que as fontes de informação serão vasculhadas, diferenciadas e monitoradas depende das características do meio profissional ou social do indivíduo, inclusive da estrutura e da cultura da organização, e da disponibilidade e do acesso à informação" (CHOO, 2003, p. 115). Sob essa ótica, o sistema de informação não é sempre um único sistema, mas, sim, é percebido com o sistema social, com foco nos comportamentos dos sujeitos informacionais. 
Choo (2003) reforça que o comportamento das pessoas que buscam e usam informação deve ser analisado em três níveis, que compreendem os aspectos emocional, cognitivo e o situacional nos quais o sujeito informacional está envolvido. E examina os efeitos das necessidades cognitivas, as reações emocionais e as demandas situacionais sobre o indivíduo em cada estágio - de necessidade, busca e uso.

Esses níveis são apresentados a partir dos três modelos informacionais que são fonte para a proposta de Choo: o modelo de Sense-Making, proposto por Brenda Dervin (1996), que explora o aspecto cognitivo, de criação de significado; o modelo de Carol Kuhlthau (1991), que prioriza o emocional; e o modelo de Taylor (1991), que prioriza o situacional.

Para Choo, a abordagem cognitiva da criação de significado é apoiada na teoria desenvolvida e aplicada por Brenda Dervin (1996) - o Sense-Making. Com origem na área de Comunicação Social, é focada em estudos orientados aos usuários frente a seus comportamentos e relações no processo de uso da informação. Considera as relações do indivíduo, suas experiências e o contexto e o trajeto para que a informação faça sentido. A construção dos sentidos se dá a partir das experiências dos sujeitos, sendo elas culturais, sociais, políticas e econômicas. A intenção do modelo é avaliar como a informação é usada no processo em que as pessoas constroem percepções sobre a realidade. A metodologia considera a necessidade de informação e a existência de um gap na base de conhecimento do usuário e inquietações, que leva à necessidade de sentido a partir da correção dessa falha - para fazer sentido na comunicação.

O modelo se estrutura em quatro pontos centrais: a situação, as lacunas, os auxiliadores e as pontes. Em uma situação de busca de informação, as ideias partem de um contexto do indivíduo. O processo apresenta as lacunas, confusões, problemática e angústia que são entraves para as pessoas alcançarem seus auxiliadores. Estes, por sua vez, são as ideias ou conceitos que impulsionam para que se ultrapasse a ponte sobre as lacunas (efeitos, usos, resultados) e as pontes são ideias formadas a partir da construção do sentido (DERVIN, 1996).

Carol Kuhlthau (1991) foca seu estudo no comportamento dos usuários e analisa o comportamento deles no processo de busca de informação, com prioridade para o fator emocional. O modelo proposto por Kuhlthau (1991), conhecido como ISP - Information Seeking Process - foi desenvolvido a partir de estudos realizados com usuários de bibliotecas, que estavam lidando com necessidades de informações impostas, e não por iniciativa própria. Seu estudo oferece uma organização de estágios do processo de busca de informação em seis 
etapas: iniciação, quando o indivíduo reconhece a necessidade de informação; seleção, quando identifica um tema geral a verificar; exploração, quando investiga as informações sobre o tema geral; formulação do foco; coleta $e$ reunião das informações relacionadas ao foco formulado; apresentação, em que completa a busca de informação e resolve o problema. Nesse processo, sentimentos se misturam em momentos de otimismo, insegurança, confusão e clareza, confiança e alívio, e o comportamento emocional é um forte influenciador do processo. A busca é iniciada com um sentimento de incerteza e ao final surge uma sensação de satisfação.

Robert Taylor (1991) apresenta um modelo que contempla as dimensões situacionais do processo informacional, com ênfase no contexto organizacional em que ele ocorre. O contexto situacional refere-se aos diversos ambientes e situações de uso da informação, nos quais o indivíduo do processo organizacional está inserido e que influenciam seu comportamento. No contexto estão incluídos o meio social do sujeito da informação e os ambientes do uso de informação. Choo (2003) afirma que, a partir dos pressupostos de Taylor, é possível entender os grupos de pessoas consideradas suas características demográficas e não demográficas. Por exemplo, preferências por fontes ou canais de comunicação por determinados grupos profissionais. As situações problemáticas do ambiente informacional sugerem como elaborar as necessidades de informação, do sujeito e demandas da situação.

\section{Metodologia}

A metodologia da pesquisa englobou um processo misto, sendo inicialmente quantitativo, seguido de uma etapa qualitativa, de estudo de casos múltiplos, permitindo a integração das duas abordagens. Na fase quantitativa foi feita aplicação de questionário em formato de Survey num universo de 211 empresas, possibilitando a avaliação e elaboração de dados estatísticos para apresentação de perfil das empresas e verificação de questões relacionadas ao processo de busca de informações e uso de fontes. Entre os respondentes da etapa quantitativa, foi feita a seleção de uma amostra intencional de 6 (seis) empresas, para desenvolvimento do estudo de casos múltiplos, que incluíram a realização de entrevistas semiestruturadas e análise de documentos, na perspectiva de Yin (2001).

Nessa etapa qualitativa, foi aplicada a técnica do Incidente Crítico, proposta por Flanagan (1973), que consiste em avaliar os comportamentos em uma determinada situação a 
partir de uma ocorrência recente, para, no relato desse fato, observar como se deram os comportamentos e quais foram os resultados e consequências em cada situação.

Na primeira etapa, a pesquisa quantitativa avaliou o processo de gestão do conhecimento nas empresas, especialmente no que diz respeito ao acesso ou não, por parte dos empresários, às fontes de informação, para identificar em que medida "conhecem" as informações de que precisam, se existe o processo de busca das mesmas e a criação de significado.

$\mathrm{Na}$ segunda etapa, foram aplicadas entrevistas semiestruturadas, para verificar os comportamentos de busca de informação em 6 (seis) empresas selecionadas pela pesquisadora, a partir de uma amostra não probabilística por julgamento, sendo 3 (três) que indicaram maior perfil para o processo de busca de informação e 3 (três) que tiveram baixa disponibilidade de tempo de busca de informações. No roteiro de entrevista semiestruturada, abordou-se inicialmente o comportamento de busca dos pesquisados, levando-se em conta a proposta de Dervin (1996), o modelo de Kuhlthau (1991) e as variáveis de contexto, baseadas na proposta de Taylor (1991). As empresas foram ainda avaliadas em relação à evolução do radar de inovação no ALI SEBRAE CNPq.

As empresas com foco em moda, do Programa ALI em Belo Horizonte, totalizaram 220 (duzentas e vinte) empresas com número de Cadastro Nacional de Pessoa Jurídica (CNPJ), e, para a amostragem deste estudo, foram consideradas 211 (duzentas e onze) empresas, sendo 9 (nove) delas eliminadas por terem caráter apenas industrial. Posteriormente, chegou-se a uma amostra útil de 140 (cento e quarenta) empresas, tendo sido descartadas as empresas que fecharam, foram vendidas ou quando se constatou uma coincidência de sócios ou gestores. $\mathrm{O}$ questionário foi enviado em dezembro de 2018. Ao todo, num período de 55 dias, usando a estratégia on line de respostas, foram obtidas 35 respostas, correspondendo, na fase quantitativa, a um índice de $25 \%$ de retorno. 


\section{Resultados da pesquisa}

No que diz respeito ao porte das empresas, entre os respondentes, $45,7 \%$ são de empresas de micro porte, e 54,3\%, de pequeno porte. A maioria é empresa varejista de artigos de vestuário e acessórios (65,71\%), seguida por empresas de calçados $(11,48 \%)$.

Percebeu-se um caráter familiar no organograma dessas empresas, além da tendência de maior participação de mulheres $(54,3 \%)$. A maioria dos pesquisados $(60 \%)$ tem entre 30 e 50 anos, 14,29\% tem menos de 30 anos, e 25,71\%, acima de 50 anos. Em termos de escolaridade, $25,71 \%$ dos participantes não têm formação superior completa, 48,57\% têm essa formação, e 25,71\% têm pós-graduação (incompleta ou completa). A maioria dos respondentes tem formação na Área de Administração ou Finanças (40,0\%).

Do total, $17,15 \%$ indicaram que não têm sistema de Gestão Comercial e fazem registros de dados manualmente; $82,85 \%$ usam sistemas e softwares de gestão de diferentes marcas e/ou fabricantes.

Um dos pontos de atenção neste estudo é a dedicação intencional ou não para o processo de busca de informações. Autores como Drucker (2011) e Porter (1989) apontam a falta de informação como relevante para insucesso ou mortalidade das empresas. A pesquisa identificou que, no grupo estudado, a maioria dos empresários tem consciência da importância da informação e, para além disso, da sistemática de pesquisar e usar as informações - donde se conclui que não se trata da inexistência de informação, mas sim da falta de uso da mesma. $97,1 \%$ dos respondentes usam tecnologia para pesquisa de informações para a empresa. $88,6 \%$ dedicam-se especificamente e de forma consciente à atividade de busca de informações. Em relação ao tempo dedicado para o processo de busca de informações, 51,4\% dos pesquisados informaram que dedicam mais de 5 horas semanais a isso.

No que tange o perfil de loja, viu-se que quanto mais exclusivo e focado no mercado de luxo, maior o número de horas na busca de informação. 100\% das empresas de Alta Costura apontaram mais de 10 horas semanais, e as empresas da chamada "modinha" (moda popular) têm $50 \%$ com até 5 horas semanais para o processo de busca de informação. Esse dado é reincidente na etapa qualitativa da pesquisa, que será detalhada adiante, quando alguns entrevistados comentam que quanto mais exigente e até sofisticado é o público, maior a necessidade de busca de informação. 
Em relação à frequência de busca de informações, tendo como base as arenas de Choo (2003), as respostas dos participantes da pesquisa indicam que os gestores e proprietários realizam as buscas de informação, havendo um equilíbrio entre o contexto da ação para monitorar o mercado, para gerar novos conhecimentos que levem à inovação e para a tomada de decisão.

De modo geral, percebe-se que as fontes mais próximas e conhecidas pelos empreendedores de varejo de moda são as mais relevantes: clientes (71,4\% de relevância); Redes Sociais (65,71\%); Sócios e empregados (57,14\%); buscadores Web (57,14\%). Fontes mais tecnológicas, como podcasts, webconferências e fontes governamentais, estão entre as menos seguidas (31,43\% de irrelevância).

As 6 (seis) empresas que participaram dessa etapa têm uma prática de varejo multimarcas, com perfil de loja de rua. No mix de produtos das lojas, não existe a dependência de uma marca mais forte, sendo todas com variedade de fornecedores, além de perfil de produtos variados. Duas entrevistas referem-se a empresas de pequeno porte e as demais a microempresas. É interessante salientar que todas essas 6 (seis) empresas tiveram, entre os anos de 2015 a 2017, acompanhamento de um agente do ALI.

O motivo de entrada no negócio de moda se dá sobretudo por referência familiar, e a maioria das empresas tem parentes como sócio no negócio. De modo geral, verificou-se que uma relação familiar prévia influenciou a decisão dos empresários em optar pelo varejo de moda. No estudo de Albino (2000), essa questão também se confirma na indústria, com a questão social do empresário da MPE, que gera o comportamento humano a partir de um histórico com início no interior da família (muitas vezes inconsciente).

Everton Júnior (2017), SEBRAE (2014) e Albino (2000) indicam que existem características comuns e muito presentes no perfil do empresário da MPE. No varejo de moda, isso foi confirmado pela pesquisa. A gestão é concentrada nas mãos dos proprietários, que muitas vezes exercem atividades múltiplas. Este é um dos principais entraves no processo de busca de informações. O trabalho cotidiano das empresas e seus gestores é citado por todos os entrevistados como sendo dinâmico e não rotineiro. No entanto, todas as demais atividades são também concentradas nas mãos dos gestores, gerando uma sobrecarga, que muitas vezes é ampliada pela falta de planejamento, o que faz que o empresário necessite atuar mais em processos corretivos que proativos e previamente organizados. 
Com isso, a atividade informacional deliberada, planejada e estruturada ocorre apenas em alguns momentos e em processos que não podem faltar na empresa, como é o caso do processo de compras de mercadoria, que foi um dos mais citados como sendo o momento consciente de "pausa" para a busca de informações.

Se, por um lado, os empresários apontam essa dificuldade, o mesmo não acontece com os gerentes, que indicam que usam o tempo na empresa para o processo de busca de informações, pois isso tem que fazer parte de sua rotina, uma vez que o cliente está tão bem informado, que é necessário se atualizar constantemente para acompanhar as demandas.

A questão de ser uma empresa familiar pode afetar o processo de $\mathrm{GC}$, sob o ponto de vista positivo ou negativo. A aproximação entre os familiares na gestão da empresa é considerada positiva e observa-se que existe uma maior percepção do outro e possibilidades de trocas de informações e atuação conjunta nos processos de busca.

Outro ponto de dificuldade das empresas, pelo fato de serem de micro e pequeno porte, está na condição econômico-financeira da própria empresa, que dificulta uma infraestrutura maior ou até mesmo a terceirização de serviços que possam ser um suporte na GC. Alguns gestores e empresários discutiram sobre os altos custos de consultorias ou investimentos em fornecedores para lidarem com a informação de forma dedicada e profissional. Essa dificuldade vai além da questão de recursos, mas também da condição dos próprios fornecedores, que em alguns casos também são de pequeno porte.

Verificou-se, no grupo, a tendência de não só comercializar o produto para o público final, mas também de criar ou customizar os produtos. Com isso, surge a necessidade de monitorar constantemente informações sobre tecidos, processo produtivo, além de tendências e formas de vender. Este fator exige um novo foco de atenção para a busca de informações.

Empresas com cultura de GC, mais que Gestão da Informação, têm maior vocação para a ação, transformando informação tácita em explícita (TAKEUCHI; NONAKA, 2008), com compartilhamento e participação das equipes na criação de novos conhecimentos. No grupo pesquisado, as relações entre a equipe e os gestores e empresários são muito próximas, por serem empresas de pequeno porte e com número reduzido de funcionários. Essa questão é percebida como um facilitador no processo de busca de informações em alguns momentos. No entanto, a gestão da equipe e o preparo para o processo informacional é uma dificuldade dos 
entrevistados, pois envolve a construção do conhecimento, segunda Arena proposta por Choo (2003) e uma ação interna na empresa para conversão e integração do conhecimento.

Nas empresas, existem situações de ocultação de informações. Essa questão se alinha com o que é apontado por Choo: "não é raro haver bloqueio, atraso, ocultação ou mesmo distorção da informação" (CHOO, 2003. p. 164).

Outra dificuldade apontada, por parte das empresas, está na organização das informações internas para que sejam usadas como fonte de informação. Para ser uma fonte de informação, é importante se conscientizar sobre o fluxo da informação (insere no sistema, organiza, mantém, usa, passa a ser fonte e é alimentada constantemente). Essa é uma realidade difícil para algumas empresas, que alegam que dispõem do sistema, mas as informações (dados sobre clientes, produtos, estoque) não estão inseridas nele.

A questão situacional, que apresenta como as demandas moldam as necessidades, e como o gestor organiza a busca, é bastante aparente nas entrevistas. O modelo de Taylor (1991) mostra que o meio profissional interfere na busca de informação e no acesso às fontes, tanto quanto na condição para que o usuário molde as tarefas que serão feitas para o processo e a rotina da busca. Foi possível perceber como a facilidade de uso da fonte, a sua qualidade e ainda a redução de ruídos, são importantes para os entrevistados. Além da infraestrutura, o contexto informacional influencia a situação de busca da informação. Estes devem estar presentes na empresa, para que o processo de busca possa ser uma realidade.

Aqui, os sistemas internos ou de acesso das empresas podem promover uma maior facilidade na busca, por aumentarem a disponibilidade de informações. Por outro lado, o excesso de dados dificulta a trajetória informacional nessa fase.

No caso de empresários que têm mais de uma loja ou mais de um tipo de negócio, com públicos distintos, foi observado que acreditam haver uma diferença no processo informacional.

A questão cognitiva e as estratégias para superar as lacunas e enfrentar os vazios, apontadas por Brenda Dervin (1996), foram também identificadas nos relatos dos empresários. Eles buscam impulsionadores e condições auxiliares para ultrapassar os gaps e criar sentido no processo informacional. Uma das formas para fazer isso é a constante validação das informações e a forma como contorna as pausas e pontos de "parada" no processo, para obter as informações desejadas. Isso faz que as ambiguidades e incertezas sejam contornadas, 
gerando um equilíbrio com as percepções dos gestores e empresários. É feita uma sondagem, e os fatos que apoiam a busca de informação são analisados de forma mais dedicada.

A questão afetiva mostra como as emoções e o estado psicológico dos sujeitos influenciam na busca. Foram percebidos sentimentos diversos nas distintas etapas de busca indicadas pelos usuários. Os empresários e gestores, quando percebem a necessidade de alguma informação, partem de uma situação de incerteza e vazio e, então, iniciam o processo com uma vaga percepção sobre o assunto. Na criação de significado, inclusive, a memória afetiva do próprio usuário pode ajudar no processo de busca de informação, a partir de uma associação de conteúdos anteriores - aos quais o usuário já teve acesso. Essa afirmação aparece no relato dos empresários, que indicam que a experiência anterior ou outras experiências ajudam a terem maior segurança no processo de busca de informação e que este gera menor angústia ou dúvidas.

Conforme o modelo de Carol Kuhlthau (1991), quando o usuário está no processo de busca de informações, algumas etapas claras são presentes: iniciação, seleção, exploração, formulação, coleta e apresentação. Essa questão fica muito evidente nas entrevistas, e é reconhecida pelos empresários e gestores, que trazem um comportamento de superar as etapas uma a uma, como se estivessem complementando estágios, passando de um ao outro para conseguir atingir as informações das quais necessitam. E muitas vezes essas etapas são relacionadas com a seleção e exploração das fontes de forma mais intensa.

As fontes de informação mais indicadas pelos entrevistados podem ser de certa forma categorizadas de acordo com o objetivo de busca de informação no qual estão atuando. Quando há um processo de busca, usualmente os entrevistados citaram que buscam fontes internas - no próprio sistema de gestão da empresa e equipe e fontes externas - em especial com fornecedores, redes sociais, avaliando a concorrência e outras lojas.

Mas uma confirmação que as entrevistas trouxeram foi a existência de um procedimento de uso de fontes diversas que possam ser confrontadas ou que permitam uma validação das informações. Essa é uma dinâmica apresentada por Choo (2003), segundo a qual, nas situações de criação de significado, a ambiguidade é alta, e a ação vai acontecendo uma em consequência da outra. Assim, os usuários da informação apresentam um comportamento de acionar fontes mais próximas e mais precisas, que podem ser mais confiáveis. 
No caso do cliente, a escolha como fonte das mais citadas pode ser justificada pelo fato de ele ser visto como uma autoridade, uma garantia sobre a aceitação de produtos ou tendências e ainda pelo fato de estar mais presente e próximo dos entrevistados.

Não existe uma entrega completa a uma única fonte, e mesmo as mais relevantes para a busca são acessadas pelos entrevistados, com cuidados e uma certa combinação e cruzamento de dados, de forma a se ter menor risco no uso das mesmas para a tomada de decisão ou entendimento do mercado e geração de conhecimento.

A frase mais recorrente, nas entrevistas, foi: “A informação está na palma da minha mão". Dos 6 entrevistados, 5 deles citaram literalmente esse jargão. Os celulares, tablets e computadores deixam a informação mais perto e ao alcance imediato para os empreendedores. No entanto, existe um cuidado com fontes digitais e a questão da alta exposição, e esse é um entrave para os empresários e gestores. Sobre as blogueiras e credibilidade das fontes, alguns citaram que as consultam, no entanto, com algumas restrições.

O excesso de informações aparece como um grande diferencial do setor de moda, para todos os empresários, que celebram a facilidade de acesso a fontes e como o meio digital colabora com as ações de busca de informações. Por outro lado, as questões abordadas por Lipovetsky (2009), sobre o caráter efêmero da moda e a constante mudança ou mesmo a agilidade com que as informações são criadas, são indicadas como um forte entrave para os empresários e gestores. Isso se dá por não haver uma segurança na informação de moda, ou pela existência de tantos agentes formadores de conteúdo. 


\section{Considerações finais}

Neste estudo sobre o varejo de moda, fica claro que a geração de informações parte de ambientes especializados e não especializados, formando uma grande teia de conhecimento (formal e informal) sobre a área e seu universo. Neste âmbito, a abundância de fontes informacionais, programas, tecnologias e conteúdos indica um campo de estudo vasto.

A pesquisa confirma a busca de informações como um terreno rico em análises, condutas, etapas e relações que o usuário desenvolve. Tal trajetória pode ser facilitada por recursos tecnológicos, administrativos e pessoais. $\mathrm{O}$ varejo de moda revelou-se, por um lado, gerador de informações e, por outro lado, demandante de informações. A importância econômica do setor e a amplitude de sua cadeia são resultado de dinâmicas ágeis do mercado, da integração e organização das empresas e da estrutura existente para ação de seus colaboradores e parceiros.

Nas MPE's de moda em BH, a figura do empreendedor e gestor, no centro das atividades e como um integrante que atua na rotina destas empresas, traz para a dinâmica informacional uma centralização de dados que favorece a percepção das necessidades e agiliza a busca de informações. Percebeu-se, a partir da pesquisa, que o tamanho das empresas e a complexidade delas tem uma interferência no fluxo de informações.

Por mais que se perceba a existência de entraves, enfim, a pesquisa sublinha quão importante é organizar a teia do conhecimento, para propiciar um processo organizado de busca, que gere melhores condições de uso.

O campo estudado é vastíssimo, e esta pesquisa abre horizontes para muitos desdobramentos e perguntas. Entraves existem. No varejo de moda, como possivelmente em muitos outros espaços e setores, as dificuldades diminuem sensivelmente quando o gestor conhece sua teia como um todo e cada um de seus fios, e a forma de articular-se com outras tantas teias - o que, certamente a busca da informação e a sua gestão ajudam substancialmente a se atingir. 


\section{Referências}

ALBINO, Maria Eugenia Coelho Andrade. A informação tecida na moda: o campo das micro e pequenas indústrias do vestuário em Minas Gerais. 2000. Tese (Doutorado em Ciência da Informação) - Programa de Pós-Graduação em Ciência da Informação do IBICT/CNPq, ECO/UFRJ, Rio de Janeiro, 2000.

BLACKMAN, Cally. 100 anos de moda. São Paulo: Publifolha, 2012.

BOURDIEU, Pierre. O costureiro e sua grife: contribuição para uma teoria da magia. Educação em Revista, Belo Horizonte, n. 34, dez. 2001.

CHILDE, Vere Gordon. A evolução cultural do homem. Tradução de Waltensir Dutra. 5. ed. Rio de Janeiro: Zahar, 1981.

CHOO, Chun Wein. A organização do conhecimento: como as organizações usam a informação para criar significado, construir conhecimento e tomar decisões. São Paulo: Senac São Paulo, 2003.

CIETTA, Enrico. A revolução do fast-fashion: estratégias e modelos organizados para competir nas indústrias híbridas. São Paulo: Estação das Letras e Cores, 2010.

CONTE, Adriana Job Ferreira. Moda, uma metáfora. Curitiba: Appris, 2015.

DAVENPORT, Thomas; PRUSAK, Laurence. Conhecimento empresarial: como as organizações gerenciam seu capital intelectual. São Paulo: Campus, 1998.

DERVIN, Brenda; FOREMAN-WERNET, Lois; LAUTERBACH, Eric. Sense-making methodology reader: selected writings of Brenda Dervin's. [S. l.]: Hampton Press, 2003.

DERVIN, Brenda. Information needs and uses. Annual Review of Information Science and Technology, v. 21, 1996.

DRUCKER, Peter Ferdinandi. Inovação e espírito empreendedor: práticas e princípios. São Paulo: Cengage Learning, 2011.

DULCI, Luciana Crivellari. Da moda às modas no vestuário: entre a teoria hierárquica e o pluralismo, pelo olhar da consumidora popular em Belo Horizonte. 2009. Tese (Doutorado em Sociologia) - Programa de Pós-Graduação em Sociologia da Universidade Federal de Minas Gerais, Belo Horizonte, 2009.

EVERTON JUNIOR, Antonio. MPE: avanços importantes para as micro e pequenas empresas 2017-2018. Rio de Janeiro: Confederação Nacional do Comércio de Bens, Serviços e Turismo, 2017.

FEGHALI, Marta Kasznar. As engrenagens da moda. Rio de Janeiro: Senac, 2013. 
FLANAGAN, John Clemans. A técnica do incidente crítico. Traduzido do Psychological Bulletin, v. 51, n. 4, July 1954. Rio de Janeiro: Associação Brasileira de Psicologia Aplicada, 1973.

KUHLTHAU, Carol Collier. Inside de search process: information seeking from the user's perspective. Journal of the American Society for Information Science, Washington, v. 42, n. 5, p. 361-371, 1991.

LIPOVETSKY, Gilles. O império do efêmero: a moda e seu destino nas sociedades modernas. São Paulo: Companhia das Letras, 2009.

NONAKA, Ikujito; TAKEUCHI, Hirotaka. Criação de conhecimento na empresa: como as empresas japonesas geram a dinâmica da inovação. Rio de Janeiro: Campus, 1997.

ORGANIZAÇÃO PARA A COOPERAÇÃO E DESENVOLVIMENTO ECONÔMICO.

Manual de Oslo: diretrizes para a coleta e interpretação de dados sobre inovação. 2. ed. Paris: OCDE, 1997

PORTER, Michael. Vantagem competitiva. Rio de Janeiro: Campus, 1989.

SEBRAE. Causa mortis: o sucesso e o fracasso das empresas nos primeiros 5 anos. São Paulo: SEBRAE, 2014. Disponível em:

https://m.sebrae.com.br/Sebrae/Portal\%20Sebrae/UFs/SP/Anexos/causa_mortis_2014.pdf.

Acesso em: 12 jul. 2020.

SEBRAE. Sobrevivência das empresas no Brasil. Brasília: SEBRAE, 2016.

SEBRAE (MG). Fatores chaves de sucesso no varejo de moda. Belo Horizonte: SEBRAE, 2017.

TAKEUCHI, Hirotaka; NONAKA, Ikujiro. Gestão do conhecimento. São Paulo: Bookman, 2008.

TAYLOR, R. S. Information use environments. In: DERVIN, B.; VOIGT, M. H (org.). Progress in communication science. Norwood: Ablex, 1991.

WILSON, Thomas Daniel. Models in information behavior research. Journal of Documentation, v. 55, p. 249-270, 1999.

YIN, Robert K. Estudo de caso: planejamento e métodos. Trad. Daniel Grassi. Porto Alegre: Bookman, 2001.

Artigo submetido em: 04 maio 2019

Artigo aceito em: 06 ago. 2020 